\title{
Dipyrrole Carboxamide Derived Selective Ratiometric Probes for Cyanide Ion
}

\author{
Chun-Lin Chen, ${ }^{\dagger},+$ Yen-Hsiu Chen, ${ }^{\dagger}$ Chan-Yu Chen, ${ }^{\dagger,}$ and Shih-Sheng Sun $*{ }^{\star}$ \\ ${ }^{\dagger}$ Institute of Chemistry, Academia Sinica, 115 Nankang, Taipei, Taiwan, Republic of \\ China \\ ${ }^{*}$ Department of Chemistry and Biochemistry, National Chung Cheng University, 168 \\ University Road, Min-Hsiung, Chia-Yi, 621, Taiwan, Republic of China \\ `Department of Chemistry, National Central University, 320 Chungli, Taiwan, \\ Republic of China \\ sssun@chem.sinica.edu.tw
}

\section{Supporting Information}

Materials and General Procedures. The starting materials, $1 H$-pyrrole-2carbonyl chloride, ${ }^{1} \mathbf{4},{ }^{2}$ and $\mathbf{5}^{3}$ were synthesized according to published methods. All other chemical reagents were commercially available and used without further purification unless otherwise noted. NMR spectra were recorded on either a Bruker AMX400 (400.168 MHz for ${ }^{1} \mathrm{H}$ and $100.622 \mathrm{MHz}$ for ${ }^{13} \mathrm{C}$ ) or a Bruker AV500 (499.773 MHz for ${ }^{1} \mathrm{H}$ and $125.669 \mathrm{MHz}$ for ${ }^{13} \mathrm{C}$ ). ${ }^{1} \mathrm{H}$ and ${ }^{13} \mathrm{C}$ chemical shifts are reported in ppm downfield from tetramethylsilane (TMS, $\delta$ scale) with the solvent resonances as internal standards. Absorption spectra were obtained using a PerkinElmer Lambda 900 UV-Vis-NIR spectrophotometer. Emission spectra were recorded in air-equilibrated $\mathrm{CH}_{3} \mathrm{CN}$ solution at $298 \mathrm{~K}$ with a Fluorolog II photoluminescence spectrometer. Luminescence quantum yields were calculated relative to 9,10diphenylanthracene in cyclohexane solution $\left(\Phi_{\mathrm{em}}=0.95\right)$. Corrected emission spectra 
were used for the quantum yield measurements. Luminescence quantum yields were taken as the average of three separate determinations and were reproducible to within $10 \%$.

Anion titrations were performed using a $2.0 \mathrm{~mL}$ chemosensor solution in $\mathrm{CH}_{3} \mathrm{CN} / \mathrm{H}_{2} \mathrm{O}(9 / 1)$ titrated with a sample of the anions prepared with the same chemosensor solution to ensure the concentration of chemosensor does not vary during the titration. Absorption and emission spectra were recorded following each addition of anion. The association constants, $K$, were determined from a 1:2 stoichiometry by fitting the whole series of spectra at $1 \mathrm{~nm}$ interval using the software SPECFIT 3.0 from Spectrum Software Associates, which employs a global system with expanded factor analysis and Marquardt least-squares minimization to obtain globally optimized parameters.

\section{Synthesis}

Scheme S1
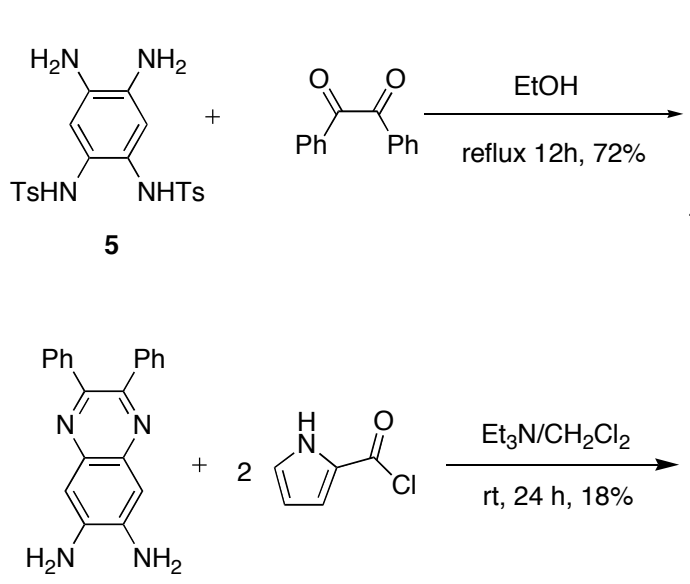

3

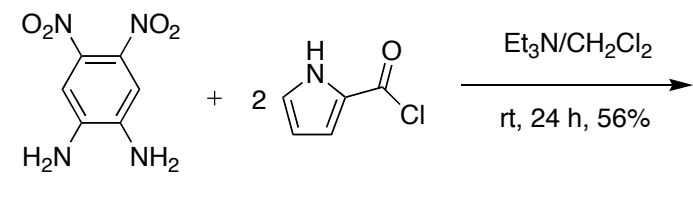

4

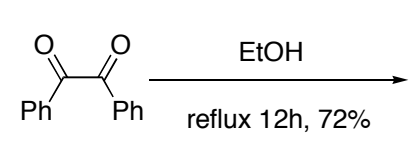

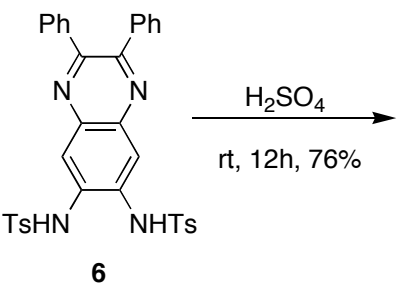
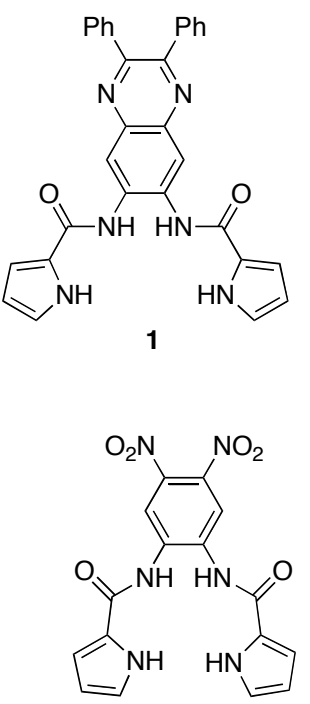

2

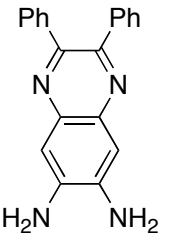

3 
Compound 6. To a 250-mL flask containing $N, N^{\prime}-(4,5$-diamino-1,2phenylene)bis(4-methylbenzenesulfonamide) (5, $890 \mathrm{mg}, 2.0 \mathrm{mmol})$ and benzil (420 $\mathrm{mg}, 2.0 \mathrm{mmol}$ ) was added $100-\mathrm{mL} \mathrm{MeOH}$ and the resulting mixture was refluxed for $12 \mathrm{~h}$. After cooling to room temperature, the pink precipitate was collected on frit. Recrystallization from THF/ether/hexane yielded 6 as white solid (890 mg, 72\%). ${ }^{1} \mathrm{H}$ NMR (500 MHz, DMSO-d6) $\delta 2.33$ (s, 6H), 7.28-7.38 (m, 14H), 7.69-7.73 (m, 6H), $10.0(\mathrm{~s}, 2 \mathrm{H}) .{ }^{13} \mathrm{C}$ NMR $(100 \mathrm{MHz}$, Acetone-d6) $\delta 20.5,122.1,127.5,127.9,128.7$, 129.8, 129.8, 133.0, 135.7, 138.9, 139.0, 144.4, 153.6. HRFABMS: $\mathrm{m} / \mathrm{z}=621.1619$ (Calcd. $\mathrm{m} / \mathrm{z}=621.1630$ for $\mathrm{M}+\mathrm{H}^{+}$). Anal. Calcd for $\mathrm{C}_{34} \mathrm{H}_{28} \mathrm{~N}_{4} \mathrm{O}_{4} \mathrm{~S}_{2}$ : C, 65.79; H, 4.55; N, 9.03. Found: C, 65.97; H, 4.69; N, 8.96.

Compound 3. To a 50-mL beaker containing $N, N^{\prime}$-(2,3-diphenylquinoxaline6,7-diyl)bis(4-methylbenzenesulfonamide) $(6,200 \mathrm{mg}, 0.32 \mathrm{mmol})$ was added 10-mL concentrated sulfuric acid and the mixture was stirred at room temperature for $12 \mathrm{~h}$. The resulting thick deep red solution was poured into iced water and solution was neutralized with aqueous sodium carbonate. The yellow precipitate was collected on a frit to afford yellowish powder of 3 (76 mg, 76\%). ${ }^{1} \mathrm{H}$ NMR (400 MHz, Acetone-d6) $\delta 5.17(\mathrm{~b}, 4 \mathrm{H}), 7.13-7.40(\mathrm{~m}, 12 \mathrm{H}) .{ }^{13} \mathrm{C}$ NMR (100 MHz, Acetone-d6) $\delta$ 107.2, 127.4, $127.6,129.8,138.3,140.8,141.5,148.0$.

Compound 1. A mixture of $1 H$-pyrrole-2-carbonyl chloride (200 mg, 1.5 mmol) and 3 (200 mg, $0.64 \mathrm{mmol})$ in $\mathrm{CH}_{2} \mathrm{Cl}_{2}(40 \mathrm{~mL})$ and $\mathrm{Et}_{3} \mathrm{~N}(2 \mathrm{~mL})$ was stirred at room temperature under nitrogen atmosphere for $24 \mathrm{~h}$. The volatile was removed under vacuum. The residue was washed with $2 \mathrm{M}$ hydrochloric acid (20 $\mathrm{mL})$ to give yellowish brown crude product. The solid was further purified by column chromatography eluted with ethyl acetate. The yellow band was collected and recrystallized from ether to afford a bright yellow powder (57 mg, 18\%). ${ }^{1} \mathrm{H}$ NMR 
(400 MHz, Acetone-d6) $\delta 6.22\left(\mathrm{dd},{ }^{3} J=5.2 \mathrm{~Hz},{ }^{4} J=2.9 \mathrm{~Hz}, 2 \mathrm{H}\right), 7.03(\mathrm{~s}, 2 \mathrm{H}), 7.10$ (s, 2H), 7.29-7.51 (m, 10H), $8.48(\mathrm{~s}, 2 \mathrm{H}), 9.96(\mathrm{~s}, 2 \mathrm{H}), 11.09(\mathrm{~s}, 2 \mathrm{H}){ }^{13} \mathrm{C}$ NMR (100 MHz, Acetone-d6) $\delta 109.8,111.6,122.4,123.3,126.0,128.0,128.6,130.0,134.4$, 138.9, 139.7, 153.1, 160.2. HRFABMS: $\mathrm{m} / \mathrm{z}=499.1887$ (Calcd. $\mathrm{m} / \mathrm{z}=499.1882$ for $\mathrm{M}+\mathrm{H}^{+}$), Anal. Calcd for $\mathrm{C}_{30} \mathrm{H}_{22} \mathrm{~N}_{6} \mathrm{O}_{2} \bullet 0.5 \mathrm{H}_{2} \mathrm{O}: \mathrm{C}, 70.99 ; \mathrm{H}, 4.57 ; \mathrm{N}, 16.56$. Found: $\mathrm{C}$, 71.34; H, 4.54; N, 16.59 .

Compound 2. A mixture of $1 H$-pyrrole-2-carbonyl chloride and 4 (300 mg, $2.0 \mathrm{mmol})$ in $\mathrm{CH}_{2} \mathrm{Cl}_{2}(40 \mathrm{~mL})$ and $\mathrm{Et}_{3} \mathrm{~N}(2 \mathrm{~mL})$ was stirred for $24 \mathrm{~h}$ at room temperature under nitrogen atmosphere. After removal of the solvent under reduced pressure, the residue was washed with $2 \mathrm{M} \mathrm{HCl}$, ether, and $\mathrm{CH}_{2} \mathrm{Cl}_{2}$ until the filtrate was colorless. Recrystallization from acetone gave the title compound as a yellow solid (433 mg, 56\%). ${ }^{1} \mathrm{H}$ NMR (400 MHz, DMSO-d6) $\delta 6.20$ (m, $\left.2 \mathrm{H}\right), 7.05$ (s, $2 \mathrm{H}$ ), 7.03 (s, $2 \mathrm{H}), 8.55$ (s, $2 \mathrm{H}), 10.2$ (s, $2 \mathrm{H}), 11.9$ (s, $2 \mathrm{H}) .{ }^{13} \mathrm{C}$ NMR (100 MHz, DMSOd6) $\delta 110.2,113.7,121.8,124.8,125.4,135.0,138.2,159.9$. HRFABMS: $\mathrm{m} / \mathrm{z}=$ 385.0898 (Calcd. $\mathrm{m} / \mathrm{z}=385.0897$ for $\mathrm{M}+\mathrm{H}^{+}$). Anal. Calcd for $\mathrm{C}_{16} \mathrm{H}_{12} \mathrm{~N}_{6} \mathrm{O}_{6}: \mathrm{C}, 50.01$; H, 3.15; N, 21.87. Found: C, 49.79; H, 3.32; N, 21.59.

\section{References}

(1) Boatman R. J.; Whitlock, H. W. J. Org. Chem., 1976, 41, 3050-3051.

(2) (a) Acheson, R. M. J. Chem. Soc. 1956, 4731-4735 (b) Cheeseman, G. W. H. J. Chem. Soc. 1962, 1170-1176.

(3) Kleineweischede A.; Mattay, J. Eur. J. Org. Chem. 2006, 947-957.

(4) Connors, K. A. Binding Constants; John Wiley and Sons: New York, 1987. 

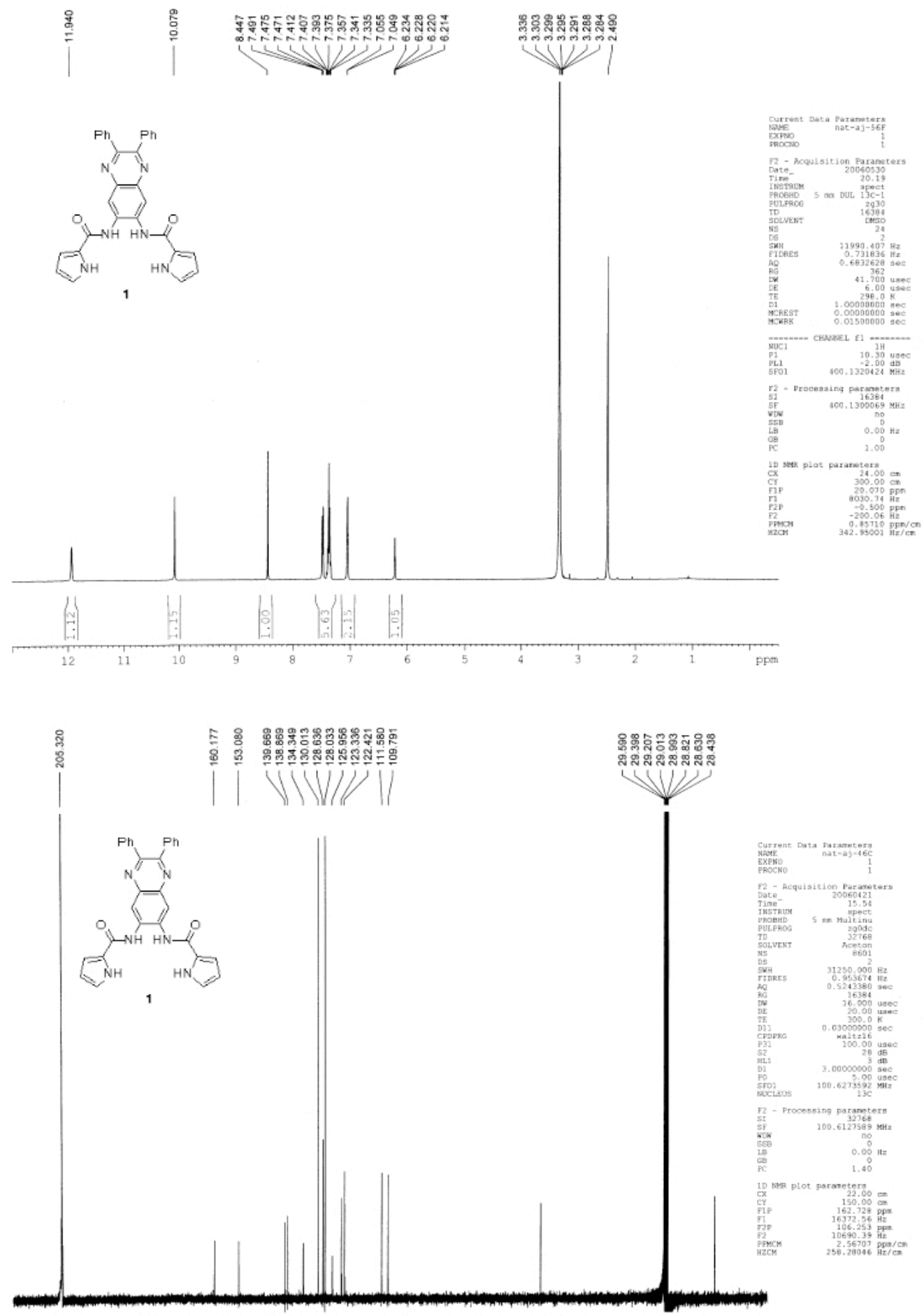


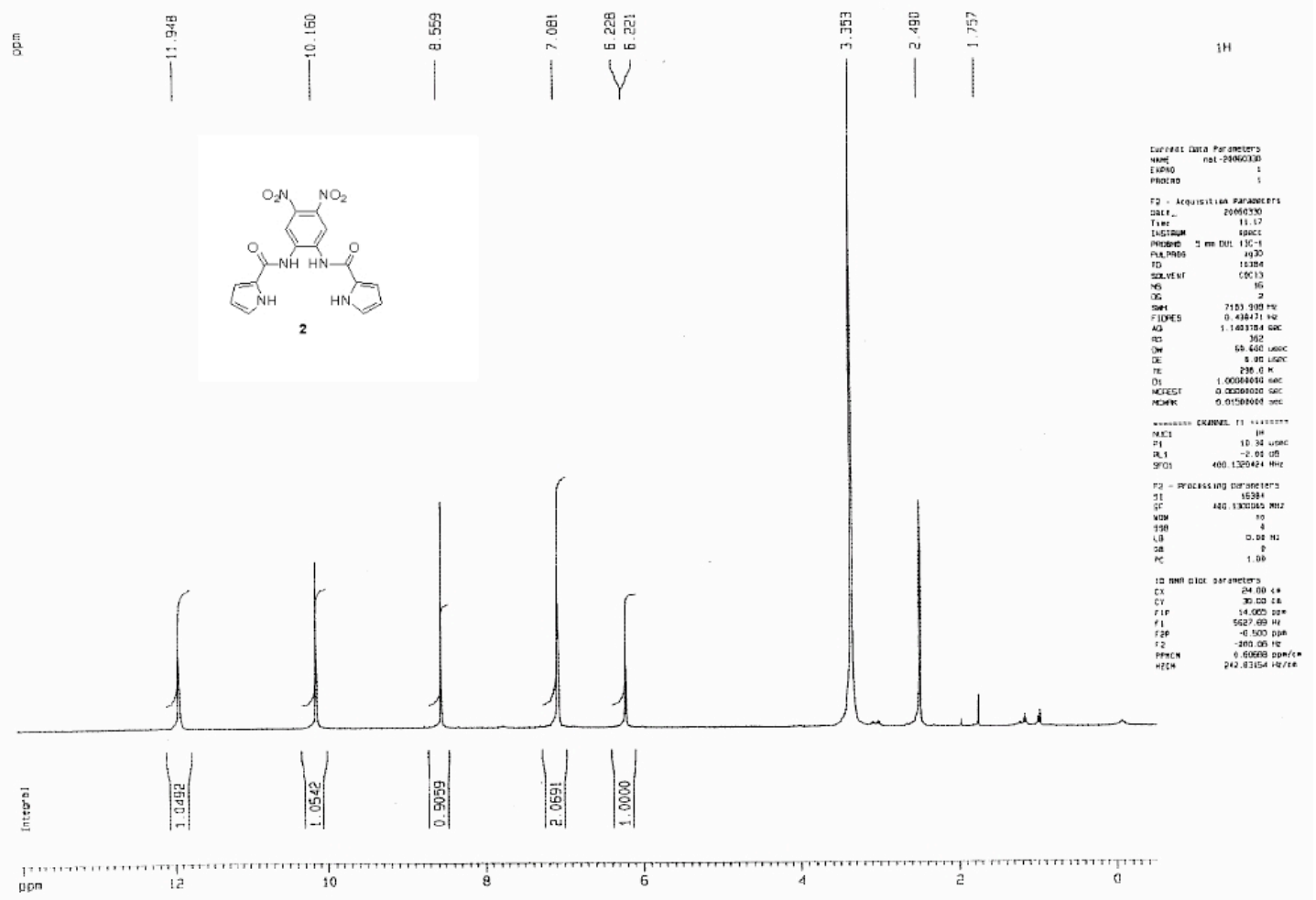

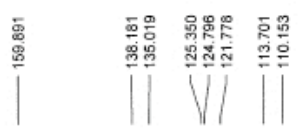
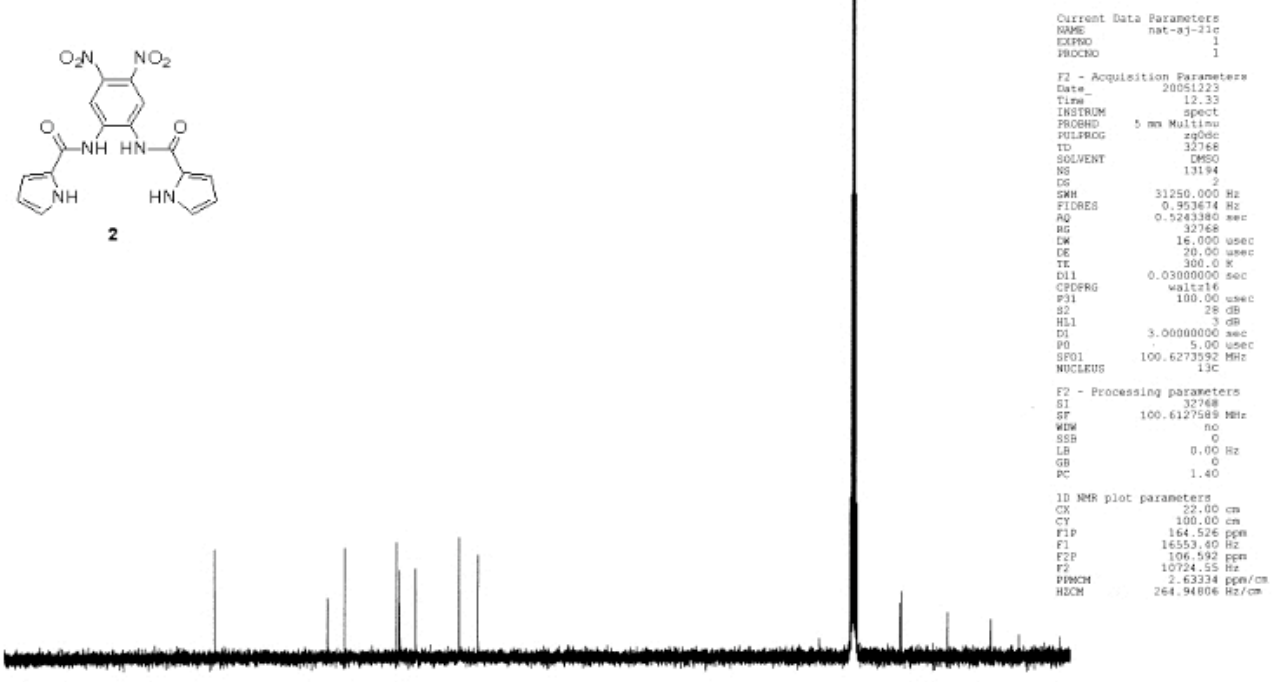

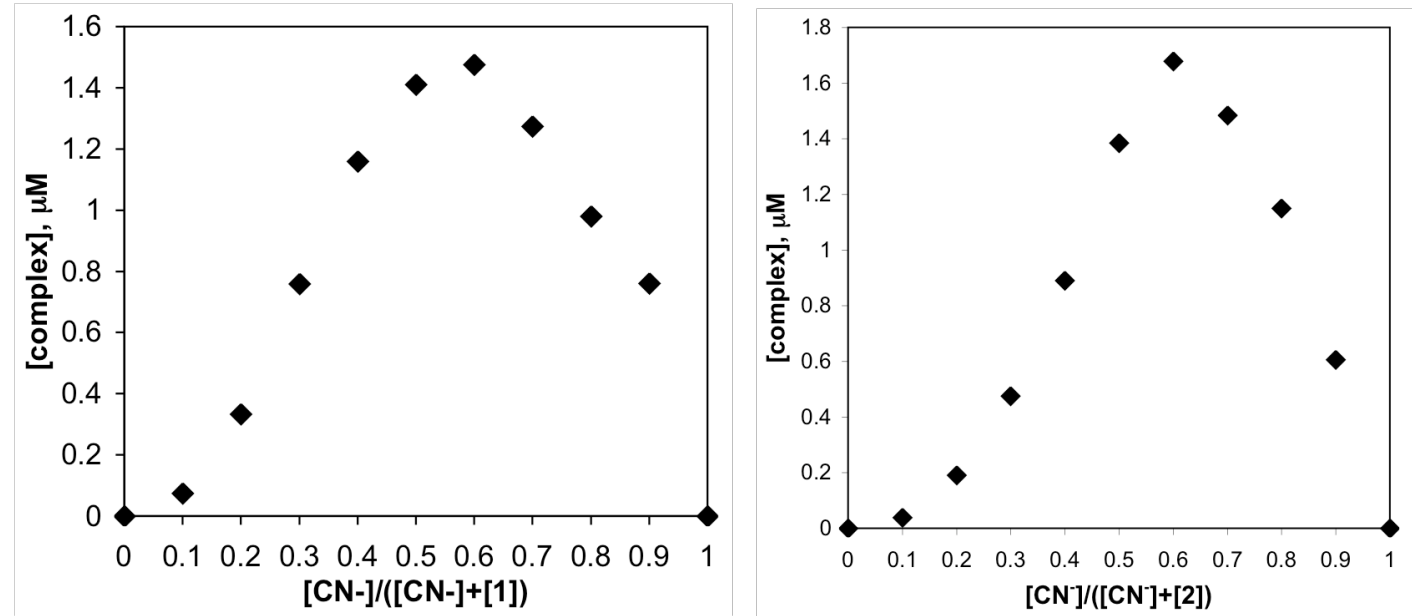

Figure S1. Job plots of $\mathbf{1}$ (left) and 2 (right).

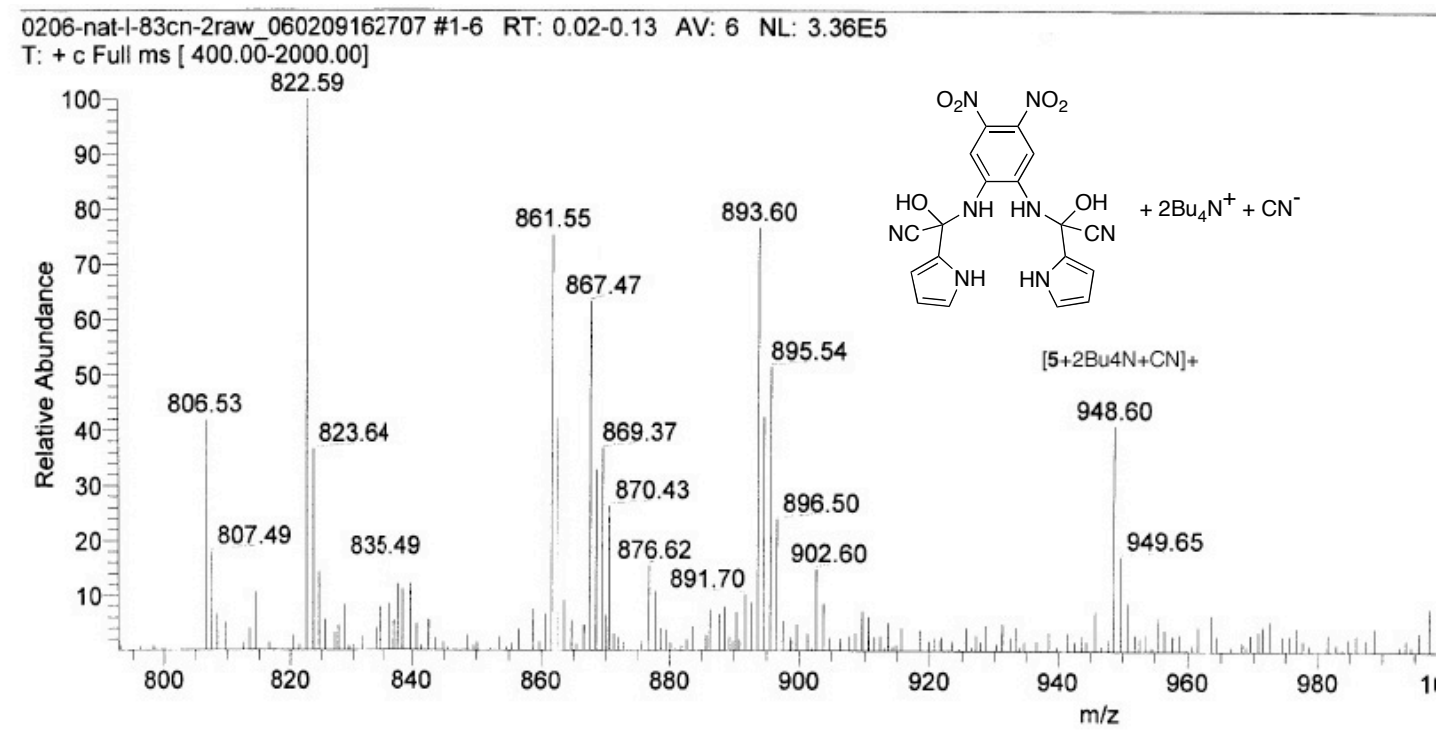

613-nataj-56ena-1 w1-10 RT: 0.01-0.21 AV: 10 NL-8.14E7

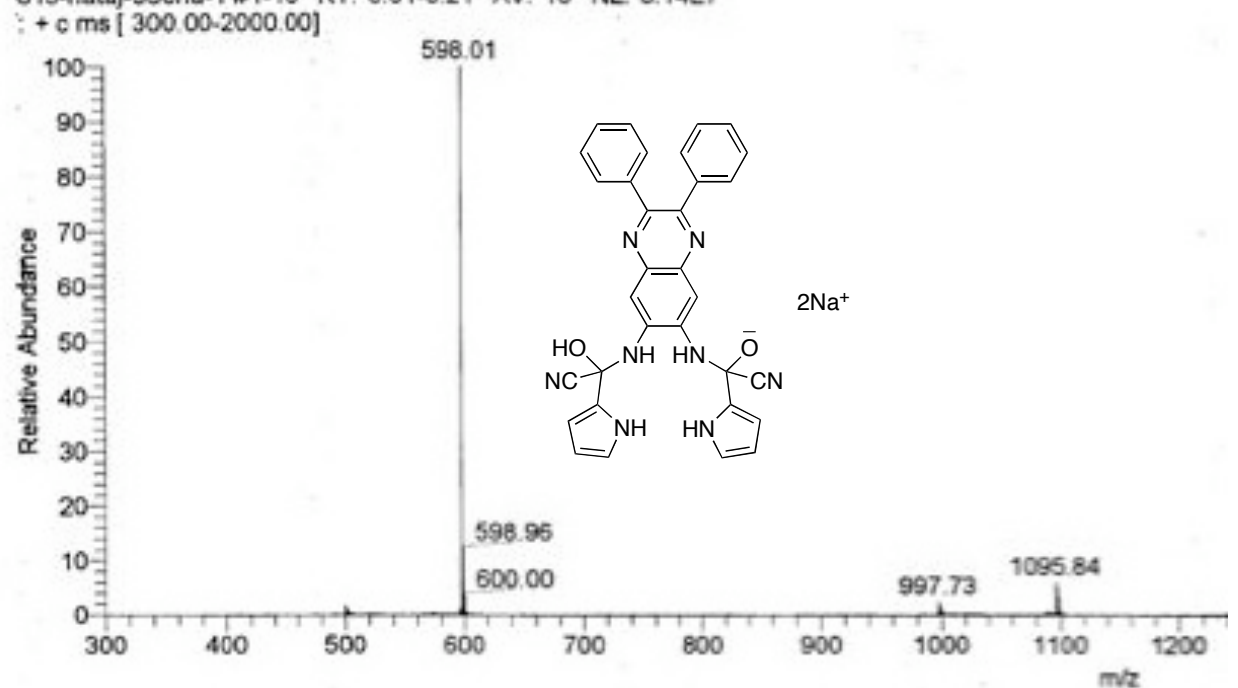

Figure S2. The ESIMS for the cyanide adducts of $\mathbf{1}$ (bottom) and $\mathbf{2}$ (top). 


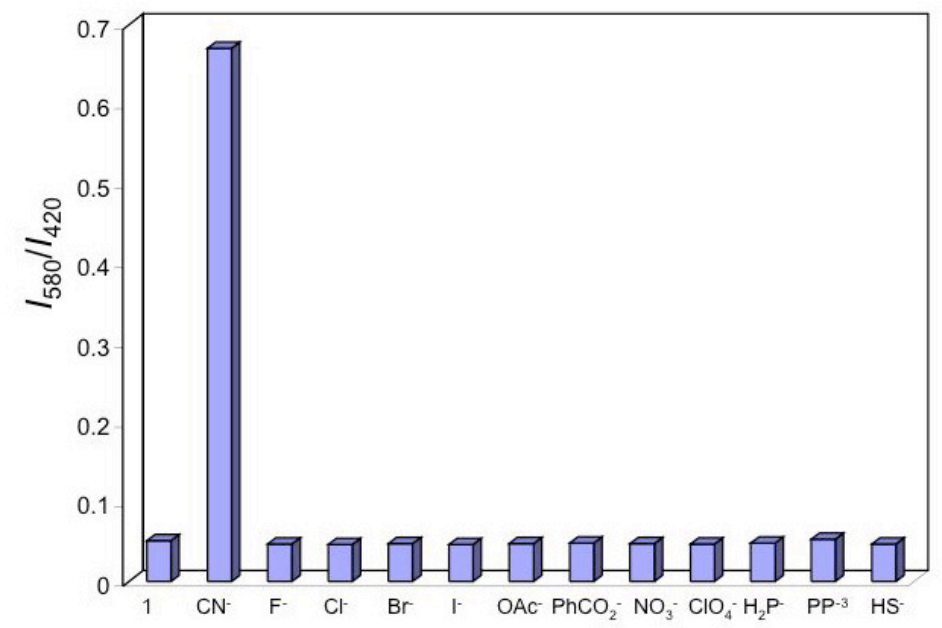

Figure S3. Ratiometric fluorescence response of chemosensor $1(20 \mu \mathrm{M})$ in the presence of 10 equivalents of selected anions in $\mathrm{CH}_{3} \mathrm{CN} / \mathrm{H}_{2} \mathrm{O}(1 / 1, \mathrm{v} / \mathrm{v})$ solution.

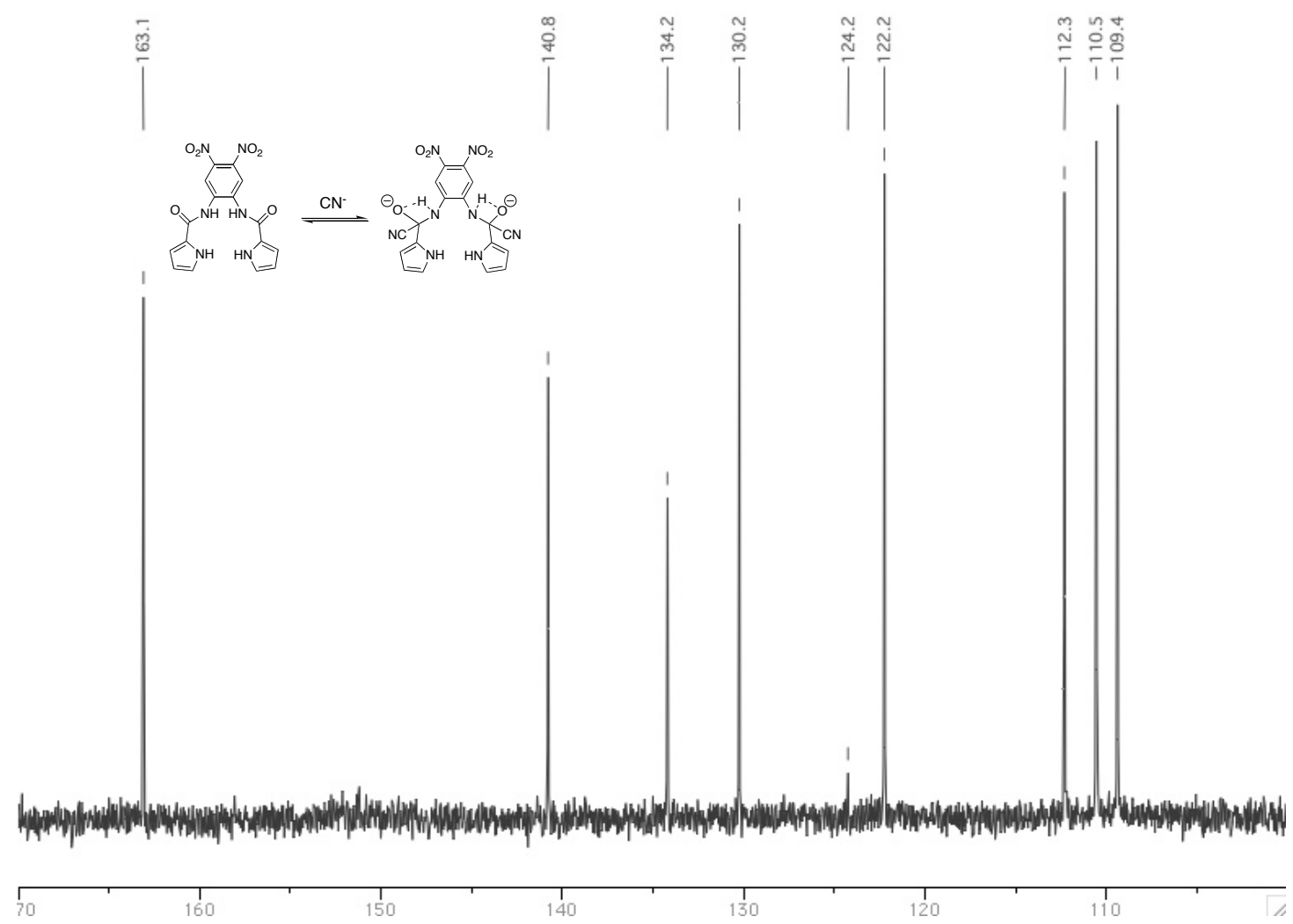

Figure S4. The ${ }^{13} \mathrm{C}$ NMR spectrum of cyanide adduct of $\mathbf{2}$ in DMSO- $d 6$. 